\title{
Feedback of mesoscale ocean currents on atmospheric winds in high-resolution coupled models and implications for the forcing of ocean-only models
}

\author{
Rafael Abel ${ }^{1}$, Claus W. Böning ${ }^{1}$, Richard J. Greatbatch ${ }^{1}$, Helene T. Hewitt ${ }^{2}$, and Malcolm J. Roberts ${ }^{2}$ \\ ${ }^{1}$ GEOMAR Helmholtz Centre for Ocean Research Kiel, Kiel, Germany \\ ${ }^{2}$ Met Office, Exeter, United Kingdom \\ Correspondence to: Rafael Abel, rabel@geomar.de
}

\begin{abstract}
The repercussions of surface ocean currents for the near-surface wind and the air-sea momentum flux are investigated in two versions of a global climate model with eddying ocean. The focus is on the effect of mesoscale ocean current features at scales of less than $150 \mathrm{~km}$, by considering high-pass filtered, monthly-mean model output fields. We find a clear signature of a mesoscale oceanic imprint in the wind fields over the energetic areas of the oceans, particularly along the extensions of

5 the western boundary currents and the Antarctic Circumpolar Current. These areas are characterized by a positive correlation between mesoscale perturbations in the curl of the surface currents and the wind curl. The coupling coefficients are spatially non-uniform and show a pronounced seasonal cycle. The positive feedback of mesoscale current features on the near-surface wind acts in opposition to their damping effect on the wind stress. A tentative incorporation of this feedback in the surface stress formulation of an eddy-permitting global ocean-only model leads to a gain in the kinetic energy of up to $10 \%$, suggesting a fundamental shortcoming of present ocean model configurations.
\end{abstract}

\section{Introduction}

During the last decade, studies of satellite observations and high-resolution coupled ocean-atmosphere models have revealed some intriguing impacts of mesoscale ocean fronts and eddies on the near-surface winds. Spurred by the identification of an imprint on the surface wind of gradients in sea surface temperature (SST) associated with meandering oceanic fronts (Xie,

5 2004; Chelton et al., 2004), a particular emphasis of research has been on the mechanisms of the thermal air-sea coupling. At mid-latitudes, air-sea interaction at larger scales shows a negative correlation between SST anomalies and surface wind, reflecting a passive role of the ocean in atmospheric forcing. The interaction is reversed at smaller spatial scales where SST anomalies exert an influence on wind speeds and surface stress via perturbations of the atmospheric boundary layer (Wallace et al., 1989; Samelson et al., 2006; Spall, 2007; Small et al., 2008), leading to a positive SST - wind stress correlation for 10 quasi-stationary frontal regions (Bryan et al., 2010; Roberts et al., 2016) and transient eddies (Frenger et al., 2013). The SST - wind (stress) coupling can have important repercussions for tropospheric weather patterns (Minobe et al., 2008), while in turn, the damping of SST anomalies by enhanced winds constitutes a negative feedback on the oceanic mesoscale (Shuckburgh 
Ocean Sci. Discuss., doi:10.5194/os-2017-24, 2017

Manuscript under review for journal Ocean Sci.

et al., 2011) that represents a dominant factor in the energetics of western boundary currents (Ma et al., 2016).

Another aspect of mesoscale air-sea coupling concerns the imprint of surface currents. It has long been recognized that current-induced vertical velocity shear can influence frictional air-sea coupling and thus can cause surface motions to decay (Dewar and Flierl, 1987; Pacanowski, 1987). Accounting for the surface current in the surface stress formulation used in ocean circulation models, i.e. the use of 'relative winds' across the interface instead of 'absolute winds' in the bulk parameterization of the turbulent momentum flux, was found to significantly (up to $30 \%$ ) reduce the energy input to the large-scale circulation (Duhaut and Straub, 2006; Zhai and Greatbatch, 2007; Hughes and Wilson, 2008; Scott and Xu, 2009) and by up to $70 \%$ in the near-inertial frequency band (Rath et al., 2013). In eddying models the eddy kinetic energy (EKE) was found to be reduced (Zhai and Greatbatch, 2007; Seo et al., 2016) due to increased surface drag (Eden and Dietze, 2009) and reduced wind energy transfer (Hutchinson et al., 2010), with implications for primary production (Eden and Dietze, 2009). Compared to the thermal interaction via mesoscale SST anomalies, the mechanical damping via the current-surface stress coupling was found to be much more dominant for the dynamics of the mean and eddy currents in a regional model study (Seo et al., 2016). In contrast Byrne et al. (2016) report that in regions with strong wind gradients like the Antarctic Circumpolar Current (ACC), the thermal effect outweighs the mechanical effect with respect to the EKE of vortices and their lifetime.

While previous work on the role of surface currents in the air-sea momentum transfer focused on the effect of surface stress changes for the energetics of the ocean, recent studies also began to consider the implications for the near-surface winds. Moulin and Wirth (2016) investigated the local exchange of momentum between idealized turbulent layers of ocean and atmosphere at the scale of ocean eddies, showing that owing to the large difference in inertia between the two components, the atmosphere can be influenced by persistent ocean features, while its short time fluctuations tend to be independent of the ocean dynamics. Renault et al. (2016b) investigated the influence of mesoscale ocean eddies on the momentum exchange in a regional highresolution coupled ocean-atmosphere model of the California Current System (CCS). They showed that the current feedback can conceptually be split into two parts: its effect on the surface stress which induces a damping on the EKE, and a subsequent effect on the near-surface winds which partly counteracts the damping and re-energizes the atmosphere (and subsequently the ocean). They found that the near-surface winds are enhanced by about $20 \%$ of the surface ocean current. Based on their

5 findings for the CCS, Renault et al. (2016b) suggest that for uncoupled ocean-only models, the partial re-energisation should be taken into account in the bulk formulae of the wind stress.

This study extends the approach of Renault et al. (2016b) by examining the air-sea momentum transfer at the oceanic mesoscale in two versions of a global climate model with 'eddy-permitting' and 'eddy-resolving' ocean components. More specifically, we use the coupled model simulations to (1) identify the imprint, including its spatial distribution, of mesoscale ocean current features on the near-surface winds over the global ocean by inspecting spatially high-pass filtered surface currents and near-surface winds; (2) to investigate its repercussion for the surface momentum flux, i.e., the effect of the current - wind feedback on the current - surface stress relation; (3) to give a preliminary assessment of its potential impacts for the mean 
Ocean Sci. Discuss., doi:10.5194/os-2017-24, 2017

Manuscript under review for journal Ocean Sci.

Discussion started: 12 April 2017

(c) Author(s) 2017. CC-BY 3.0 License.

and eddy kinetic energies of an eddy-permitting global ocean model, based on a tentative implementation of the diagnosed spatially-variable, monthly-mean distribution of the current-wind coupling in the bulk surface stress formulation.

\section{Methods \& Models}

\subsection{Methods}

Both atmospheric surface winds and ocean-surface currents determine the surface stress

$\boldsymbol{\tau}=\rho_{a} C_{D}|\boldsymbol{U}-\alpha \boldsymbol{u}|(\boldsymbol{U}-\alpha \boldsymbol{u})$,

where $\rho_{a}$ is air density, $C_{D}$ the drag coefficient (note that $C_{D}$ also depends on the choice of $\alpha$ as $|\boldsymbol{U}-\alpha \boldsymbol{u}|$ is used for the calculation), $\boldsymbol{U}$ the $10 \mathrm{~m}$ wind, $\boldsymbol{u}$ the ocean surface current and $\alpha$ a parameter representing the influence of ocean currents. Note that we chose to use the wording 'surface stress' instead of the more commonly used 'wind stress' as the stress is not entirely determined by the wind. Since the wind speed is typically an order of magnitude larger than the ocean current speed, the challenge is to detect the imprint of ocean currents in the surface stress. Fortunately the inherent spatial and temporal scales of the atmosphere and the ocean are very different. While at mid-latitudes atmospheric mesoscale variability is typically associated with time scales of hours to days and spatial scales of hundreds to thousands of kilometers, the oceanic variability is most energetic at time scales of days to weeks with spatial scales of tens of kilometers.

For assessing the imprint of the oceanic variability, we use monthly-mean model output from coupled atmosphere-ocean and forced ocean-only simulations and apply a spatial Hann-type high-pass filter to remove variability on scales longer than approximately $150 \mathrm{~km}$ (see Appendix A for discussion of this choice and associated sensitivities). Model output closer than $150 \mathrm{~km}$ to the coast is neglected as orographic and coastline effects may also introduce small-scale distortions to the wind (Perlin et al., 2007; Renault et al., 2016a).

The smallest spatial scales present in the data are emphasized further by considering the curl of the wind, of the surface stress and of the ocean surface currents in the quantification of the current-wind and current-stress linkage. Assuming linear relationship in the form

$$
\begin{aligned}
\operatorname{curl}(\boldsymbol{\tau}) 10^{2} & =s_{s t} \operatorname{curl}(\boldsymbol{u}) \\
\operatorname{curl}(\boldsymbol{U}) & =s_{w} \operatorname{curl}(\boldsymbol{u}),
\end{aligned}
$$

the coupling coefficients $s_{s t}$ and $s_{w}$ are estimated by linearly regressing the stress curl/wind curl as a function of the oceanic current vorticity. We note that other studies used bin averaging for the same quantities (Renault et al., 2016b), and for the relationship between the SST gradient and the wind curl or wind gradient (Chelton et al., 2007); however, a bin averaging was not found to be necessary here. Note also that the factor $10^{2}$ is simply used to get coupling coefficients of $\mathrm{O}(1)$. 
Ocean Sci. Discuss., doi:10.5194/os-2017-24, 2017

Manuscript under review for journal Ocean Sci.

As a means to account for the partial re-energisation of the near-surface winds in the atmospheric forcing of uncoupled ocean models, Renault et al. (2016b) proposed to tweak the bulk formulation of the surface momentum flux by using (1) with $\alpha=1-s_{w}$. From their regional model results Renault et al. (2016b) estimated an $s_{w}=0.23 \pm 0.01$ for the CCS. We extend this approach here by estimating the spatial distribution of the coupling coefficient $s_{w}$ from two global coupled simulations. We then proceed to test the suggestion of Renault et al. (2016b) by forcing a set of global ocean-only simulations using (1) with a spatially-varying parameter $\alpha$ in comparison to the classical 'absolute wind' and 'relative wind' forcing formulation.

\subsection{Models}

The coupled experiments GC2-N512 (hereafter C1/4) and GC2.1-N512O12 (hereafter C1/12) employ the atmospheric Met Office Unified Model at N512 resolution $(\sim 25 \mathrm{~km})$ and ocean components based on Nucleus for European Modelling of the Ocean (NEMO; Madec, 2011) ORCA025 and ORCA12, with a nominal resolution of $1 / 4^{\circ}$ and $1 / 12^{\circ}$, respectively. Turbulent surface fluxes are calculated (Smith, 1988) with Charnock's coefficient of 0.018, with coupling frequencies of 3-hourly (for $\mathrm{C} 1 / 4$ ) and 1-hourly (for C1/12). For an extensive documentation of the model configurations and a discussion of the impacts of a resolved ocean mesocale in the simulations we refer to Hewitt et al. (2016). A discussion of the impact of the oceanic mesoscale on the thermal air-sea interaction, i.e. the SST - surface stress relationship, has been given by Roberts et al. (2016).

Here we consider the interaction due to momentum transfer at the oceanic mesoscale. The models were integrated for 19 years (year 20 experienced some data loss), the last 15 years are used for the analysis. Even if 20 year runs might be too short for the deep ocean to spin up, they are sufficient for the surface coupling investigated in this study.

The ocean-only experiments are based on NEMO (version 3.4) in an ORCA025 configuration. This configuration uses a tripolar grid at a nominal resolution of $1 / 4^{\circ}$, and 46 vertical levels with a resolution of $6 \mathrm{~m}$ near the surface and $250 \mathrm{~m}$ at depth. Surface-forcing fields build on the Coordinated Ocean-Ice Reference Experiments (CORE, Large and Yeager, 2009; Griffies et al., 2009) and have a spatial resolution of $2^{\circ}$. Turbulent air-sea fluxes are calculated using the bulk formulae given by Large and Yeager (2004). The experiments were started from a 30-yr spinup (1980-2009) and then carried out through 1989-2004. Four forced experiments were performed: with absolute winds $\left(\mathrm{F}_{\alpha=0}\right)$, relative winds $\left(\mathrm{F}_{\alpha=1}\right)$, and two experiments that use spatially and temporally variable $\alpha$ given by the distribution of the coupled experiments $\mathrm{C} 1 / 4\left(\mathrm{~F}_{\alpha=C 1 / 4}\right)$ and $\mathrm{C} 1 / 12$ $\left(\mathrm{F}_{\alpha=C 1 / 12}\right)$. Further details are given in the next section. The analysis uses the last 15 years of each integration.

\section{Results}

\subsection{Ocean current feedback on near-surface winds}

Generally the momentum exchange between atmosphere and ocean is from the atmosphere to the ocean. In forced ocean models we find that for high-pass filtered data there is no relation between the curl of the surface current and the curl of the near-surface winds (Fig. 1 a). In coupled models, the surface stress also acts as the bottom boundary condition for the atmo- 

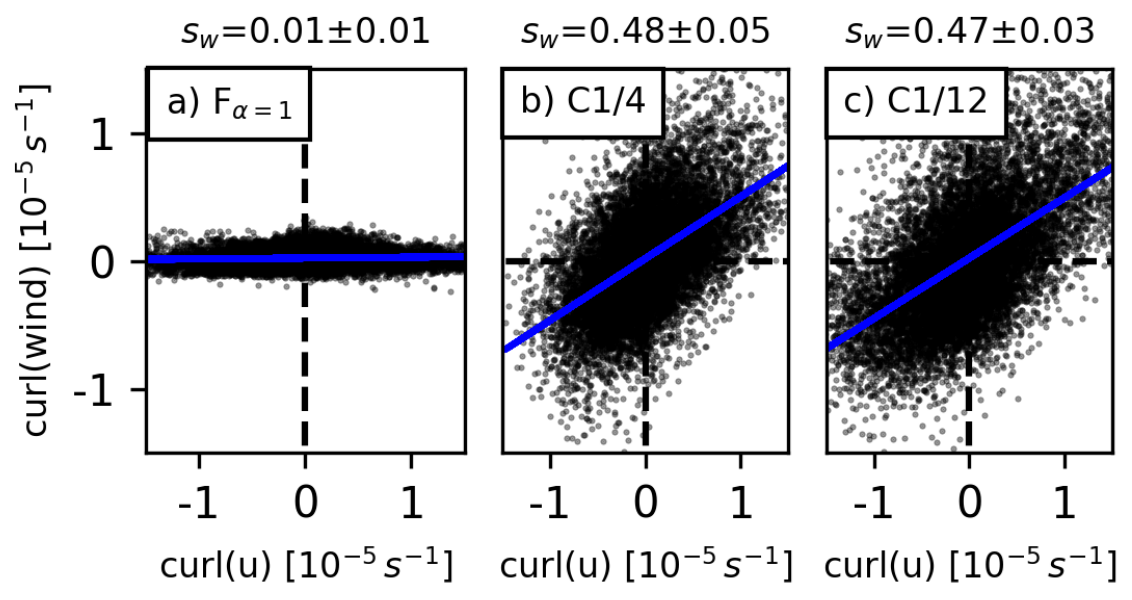

Figure 1. Influences on near-surface $(10 \mathrm{~m})$ winds by mesoscale ocean surface currents and its dependence on atmospheric stability. Relation between curl( $\mathrm{u}$ ) and curl(wind) with linear regression (blue) at the Gulf Stream (GS) Extension (35-45 $\left.{ }^{\circ} \mathrm{N}, 62-72^{\circ} \mathrm{W}\right)$ for (a) $\mathrm{F}_{\alpha=1}$, (b) $\mathrm{C} 1 / 4$ and (c) $\mathrm{C} 1 / 12$ for June. The slope of the linear regression $\left(s_{w}\right)$ is shown at the top. The standard error of the slope is calculated employing a binomial method (see Appendix C).

spheric models and thus has an impact on the near-surface winds. In contrast to the forced ocean-only simulations, the coupled simulations thus bear a relation between the curl of the ocean currents and the curl of the wind over energetic oceanic regions such as the Gulf Stream Extension (Fig. 1b,c), reflecting an influence of mesoscale ocean currents on the surface wind. The slope of the linear regression of both quantities gives the coupling coefficient for the wind $\left(s_{w}\right)$. Both coupled experiments, $\mathrm{C} 1 / 4\left(s_{w}=0.48 \pm 0.05\right)$ and $\mathrm{C} 1 / 12\left(s_{w}=0.47 \pm 0.03\right)$, yield similar estimates for the coupling coefficient, here shown for the month of June.

The influence of ocean surface currents to near-surface winds does show a strong spatial variability. Therefore $s_{w}$ is estimated in $2^{\circ} \times 2^{\circ}$ boxes over the global ocean. The largest mean values of $s_{w}$ up to 0.5 are found over the Western Boundary Current Extension (WBCE) regions and the ACC (Fig. 2; note that in weakly-energetic regions like the subtropics the method fails to diagnose a robust relationship, for more details we refer to Appendix B), while in less energetic regions the $s_{w}$ values tend to be smaller. Both coupled experiments $\mathrm{C} 1 / 4$ and $\mathrm{C} 1 / 12$ show a similar pattern, with somewhat smaller values in $\mathrm{C} 1 / 12$.

It is fair to assume that the impact of the ocean surface currents on the near-surface wind depends on the condition of the atmospheric boundary layer. Accordingly, the coupling coefficient $s_{w}$ shows a strong seasonal cycle in both coupled experiments, with larger values in summer than in winter (Fig. 3a): e.g., the values are up to 0.5 in summer and values of 0.2 in winter over the Gulf Stream Extension. The general behaviour is similar in both coupled experiments, with some quantitative differences in the amplitudes of $s_{w}$. Over the ACC (Fig. 3b) almost no seasonal cycle is found with $s_{w} \approx 0.35(\mathrm{C} 1 / 4)$ and 


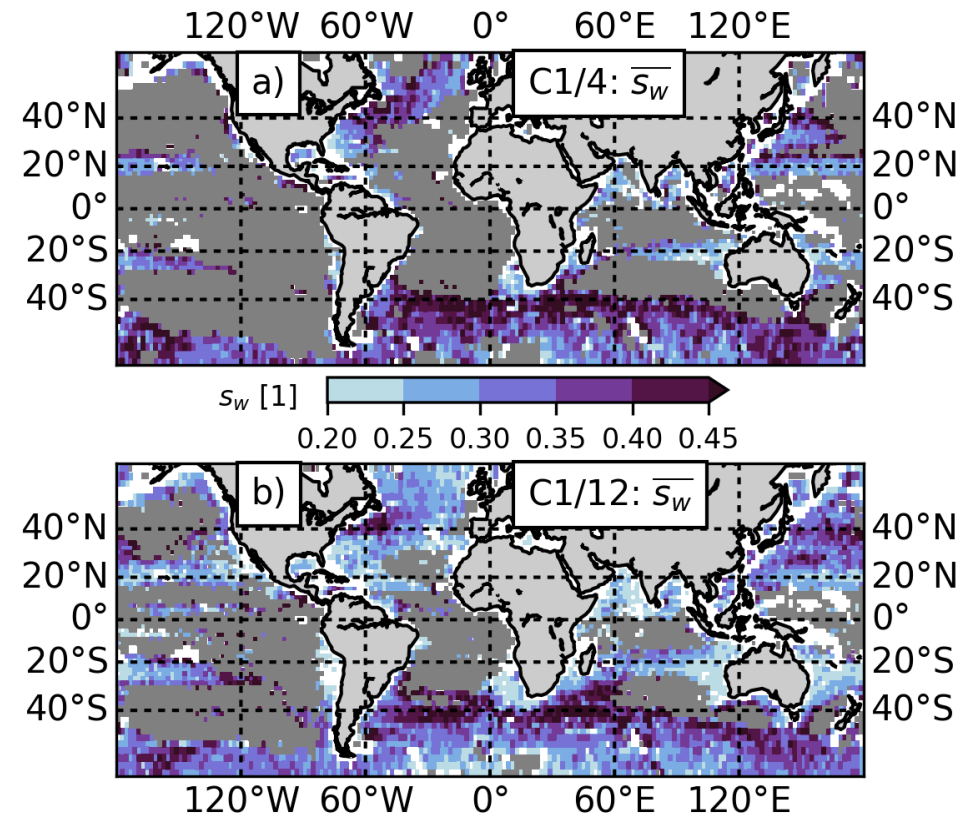

Figure 2. Mean of $s_{w}$ monthly values for (a) $\mathrm{C} 1 / 4$ and (c) $\mathrm{C} 1 / 12$. Grey shading denotes areas where the curl of the ocean currents is too small so that the estimates of $s_{w}$ are biased to too large values (see Fig. A2).

$s_{w} \approx 0.31(\mathrm{C} 1 / 12)$

The seasonality in the coupling coefficient and the different behaviour between GS and ACC regimes can be rationalized in terms of the stability of the near-surface atmosphere, as given by the vertical temperature gradient between $20 \mathrm{~m}$ and $53 \mathrm{~m}$ (Fig. 3 red curves). The relationship between the atmospheric stability and the coupling coefficient $s_{w}$ suggests that the influence of the ocean surface currents is spread over a deeper atmospheric layer when its stability is weak. More specifically, for the GS region cold winds from the continent during winter lead to strong turbulent heat fluxes over the Gulf Stream that destabilize the near-surface atmosphere, reflected by a negative vertical temperature gradient. This implies that the partial re-energisation of the winds (due to the presence of ocean currents) in winter happens over a deeper layer than during summer when the 5 near-surface atmosphere is stable (positive vertical temperature gradient). Accordingly the change in the near-surface wind is smaller in winter as the gain of momentum is distributed over a deeper layer, resulting in a smaller $s_{w}$ than in summer. During summer months the near-surface layers are relatively shallow which leads to stronger changes in near-surface winds due the presence of ocean currents, i.e. larger $s_{w}$. While the amplitude of the seasonality is similar in the north-western Pacific (Kuroshio regime), it is much smaller in the ACC regime where the monthly mean vertical temperature gradients are always 
Ocean Sci. Discuss., doi:10.5194/os-2017-24, 2017

Manuscript under review for journal Ocean Sci.
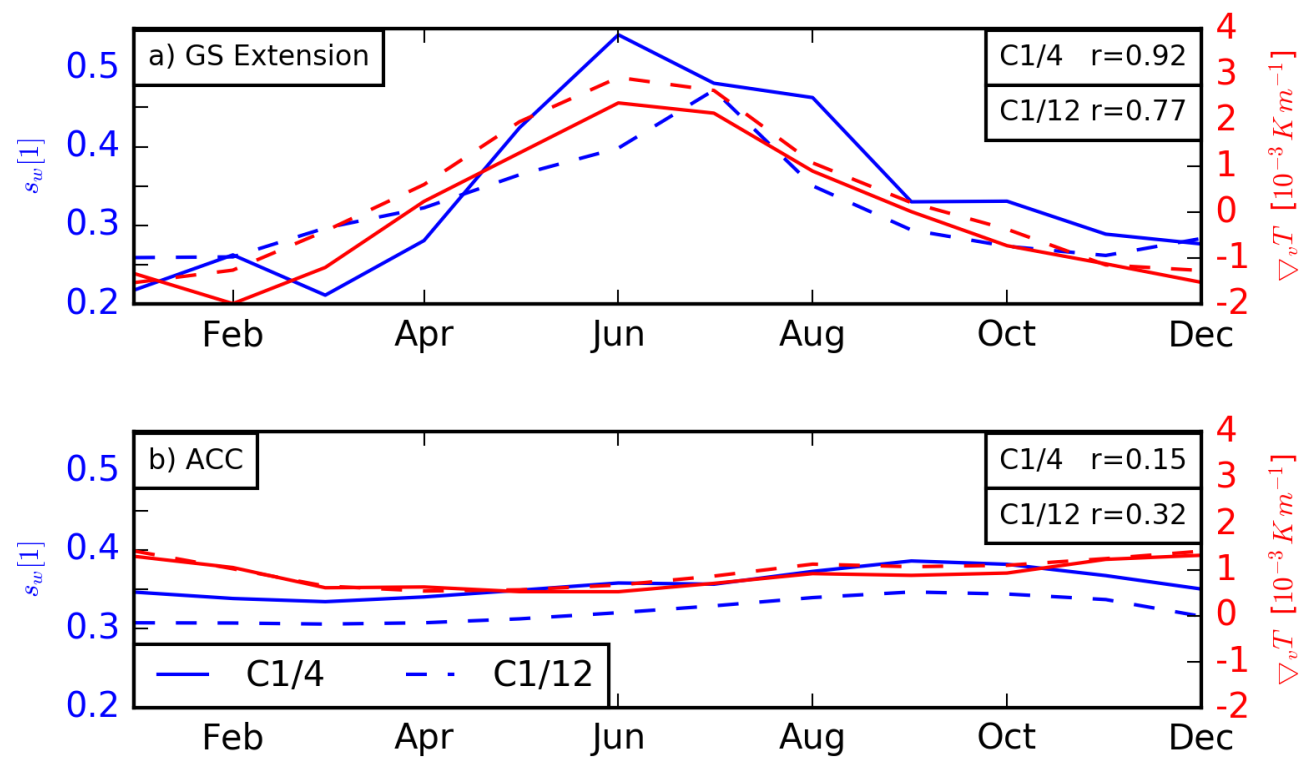

Figure 3. Seasonal cycle of coupling coefficient $s_{w}$ (blue) and vertical temperature gradient (red) T(53m) minus T(20m) for (a) GS Extension and (b) the ACC $\left(80-40^{\circ} \mathrm{S}\right)$; $\mathrm{C} 1 / 4$ (solid) $\mathrm{C} 1 / 12$ (dashed). Correlation coefficients (r) are shown at the upper right for the different experiments and regions.

positive, resulting in a large mean $s_{w}$ and very little seasonal variability (Fig. 4). The lack of a seasonality in the near-surface stability of the atmosphere also results in low correlation between the stability and $s_{w}$.

The strength of the seasonal cycle of $s_{w}$ does vary with region. An illustration of the spatial distribution of the amplitude is given in Fig. 4, showing the temporal standard deviation of the monthly-mean values of $s_{w}$. The main pattern is the contrast between the strong seasonality of the northern hemisphere WBCs and the core of the ACC reflecting the different seasonality in the stability of the near-surface atmosphere. This is emphasized in Fig. 5, showing the correlation between the variability of $s_{w}$ and near surface stability $(\partial T / \partial z)$.

The stability of the near-surface atmosphere tends to determine the strength of the coupling coefficient $s_{w}$. Over the WBCE regions the variability of the near-surface stability is high and with that the variability of the coupling coefficient $s_{w}$ is also high. Positive correlations in Fig. 5 illustrate that relation. For the WBCE of the Gulf Stream, the Kuroshio, the Malvinas, as well as for the CCS and the tropical and the subtropical oceans, the correlations are positive indicating a relation between the near-surface stability and the coupling parameter $s_{w}$. For most of the Southern Ocean the signal is small and ambiguous, with alternating positive and negative correlations. A coherent negative patch is found over the eastern North Atlantic. This however, is an area with small coupling coefficients $s_{w}$ and relatively small ocean currents, it could thus be close to the detection limit 


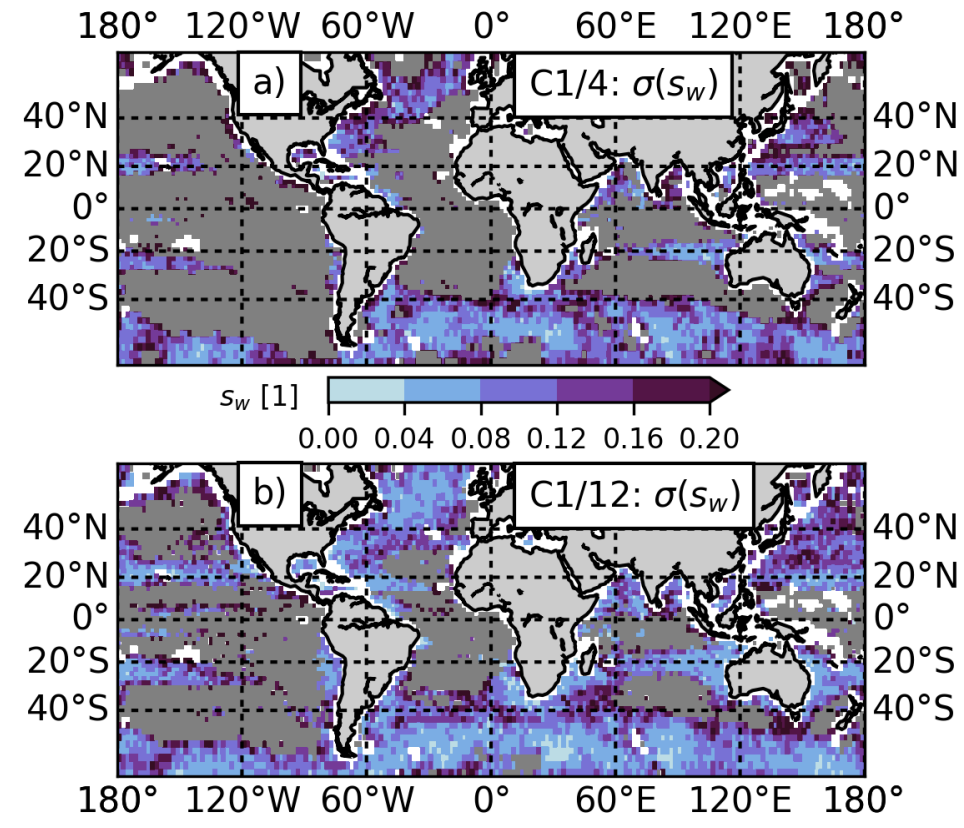

Figure 4. Standard deviation of $s_{w}$ monthly values for (a) $\mathrm{C} 1 / 4$ and (c) C1/12. Grey areas as in Fig. 2.

discussed in Appendix A.

The effect of the partial re-energisation of the atmospheric winds due to the influence of ocean surface currents in the surface stress estimation is missing in the forcing formulation currently used for ocean-only models. Renault et al. (2016b) suggest to modify the velocity used in the bulk formulation (1) by $U+s_{w} \cdot u-u$, so that the wind $\mathrm{U}$ is re-energised by $s_{w} \cdot u$, where $\mathrm{u}$ is the ocean current velocity. We then use $\alpha=1-s_{w}$ in (1) to force ocean-only models. As a test of its potential use in forced ocean-only models, following the suggestion of Renault et al. (2016b), a monthly-varying climatology of $s_{w}$ is calculated from $\mathrm{C} 1 / 4$ and $\mathrm{C} 1 / 12$ with $2^{\circ} \times 2^{\circ}$ resolution, and used in (1) with $\alpha=1-s_{w}$. For the areas with grey shading in Fig. 2 the global mean values of $\alpha=0.65(\mathrm{C} 1 / 4)$ and $\alpha=0.69(\mathrm{C} 1 / 12)$ are applied. The bulk forcing with this $\alpha\left(\mathrm{F}_{\alpha=C 1 / 4}, \mathrm{~F}_{\alpha=C 1 / 12}\right)$ is used as part of a series of ocean-only experiments. In the following sections we assess how well these experiments perform with respect to the coupled experiments. 


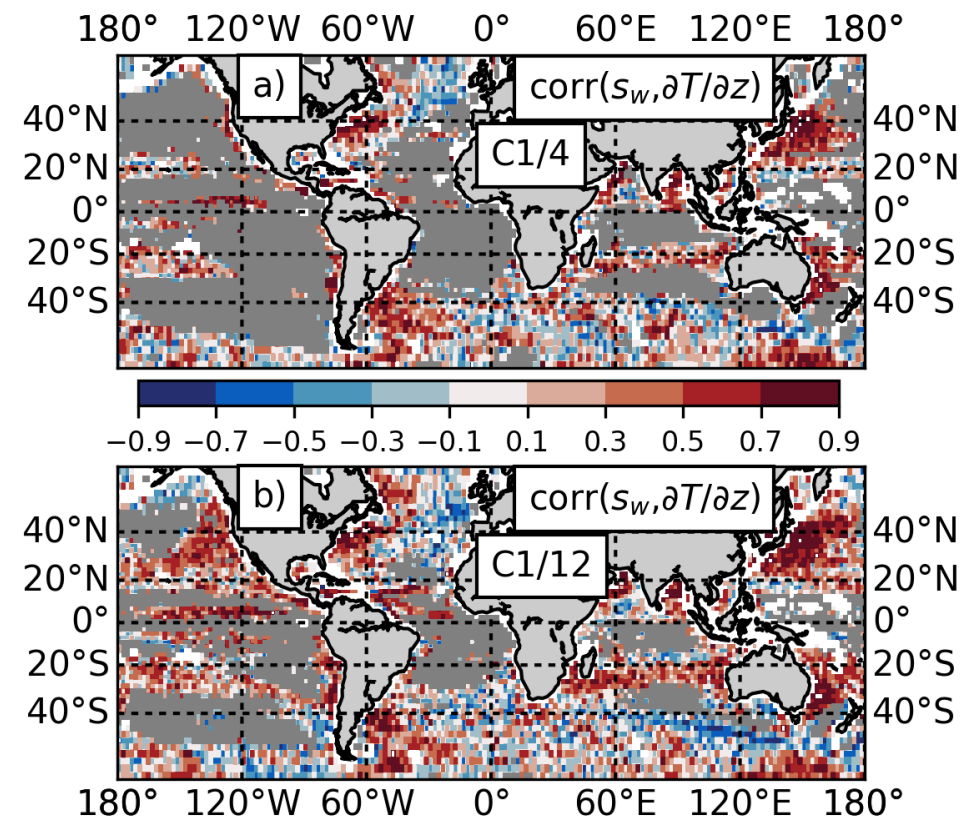

Figure 5. Correlation between the coupling coefficient $s_{w}$ and near surface stability ( $\partial T / \partial z$ ) for (a) C1/4 and (b) C1/12. Positive correlations reflect that in unstable conditions low $s_{w}$ values are found and in stable conditions high $s_{w}$ values are found. Grey areas as in Fig. 2 .

\subsection{Imprint of ocean surface currents on the surface stress}

The presence of ocean surface currents is accounted for in the surface stress formulation (1). The strength of the coupling can be expressed by the coupling coefficient $s_{s t}$ which is estimated by the slope of the linear regression between the curl of the ocean surface currents and the curl of the surface stress. The more negative $s_{s t}$ the stronger the coupling. We use $s_{s t}$ as

5 a measure of the fidelity of the momentum flux representation in the eddy-permitting, forced ocean simulations, using $\alpha=0$ $\left(\mathrm{F}_{\alpha=0}\right), \alpha=1\left(\mathrm{~F}_{\alpha=1}\right)$ and a spatially-varying field of $\alpha$ obtained from the coupled simulation $\left(\mathrm{F}_{\alpha=C 1 / 4}, \mathrm{~F}_{\alpha=C 1 / 12}\right)$. The results are illustrated for the Gulf Stream Extension in the month of January in Fig. 6 (C1/12 is not shown). In comparison to the $s_{s t}$-values for the coupled models $(-2.23 \pm 0.05)$ for $\mathrm{C} 1 / 4$ and $-2.26 \pm 0.05$ for $\left.\mathrm{C} 1 / 12\right)$, the coefficient in the relative wind simulation $\left(\mathrm{F}_{\alpha=1}\right)$ indicates a much too strong effect $\left(s_{s t}=-3.28 \pm 0.03\right)$, whereas there is no coupling in the absolute wind simulation $\left(\mathrm{F}_{\alpha=0}, s_{s t}=0.04 \pm 0.03\right)$. However, when modifying the bulk formulation by using the global distribution of $\alpha$-values obtained above, the forced ocean-only experiments were able to produce coupling coefficients $s_{s t}=-2.42 \pm 0.03$ $\left(\mathrm{F}_{\alpha=C 1 / 4}\right)$ and $s_{s t}=-2.44 \pm 0.03\left(\mathrm{~F}_{\alpha=C 1 / 12}\right)$ that are close to the estimates of the coupled experiments. This implies that the 'top drag' experienced by mesoscale features is of comparable strength in $\mathrm{C} 1 / 4, \mathrm{C} 1 / 12, \mathrm{~F}_{\alpha=C 1 / 4}, \mathrm{~F}_{\alpha=C 1 / 12}$, demonstrating 
Ocean Sci. Discuss., doi:10.5194/os-2017-24, 2017

Manuscript under review for journal Ocean Sci.

Discussion started: 12 April 2017

(C) Author(s) 2017. CC-BY 3.0 License.

Discussions

(c) $($ i)
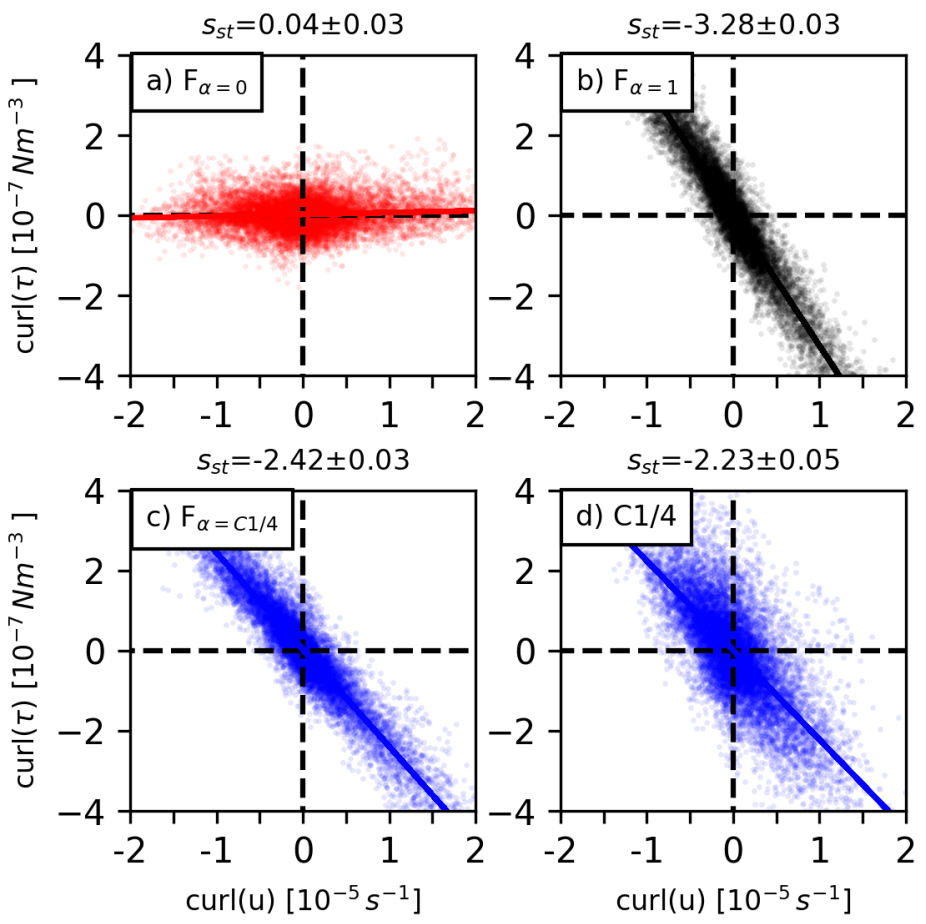

Figure 6. Ocean-surface current and surface stress coupling coefficient $s_{s t}$ for (a) $\mathrm{F}_{\alpha=1}$, (b) $\mathrm{F}_{\alpha=1}$, (c) $\mathrm{F}_{\alpha=C 1 / 4}$ (blue), and (d) $\mathrm{C} 1 / 4$ over the Gulf Stream Extension $\left(35-45^{\circ} \mathrm{N}, 62-72^{\circ} \mathrm{W}\right)$ for January. Linear regressions are depicted by solid lines; slopes and errors of the slopes are shown in the titles.

that the partial re-energisation tweak proposed by Renault et al. (2016b) is bringing the forced experiments closer to the fully coupled experiments, at least in the Gulf Stream Extension region.

The spatial distribution of the coupling coefficients obtained in the forced experiments $\mathrm{F}_{\alpha=C 1 / 4}$ and $\mathrm{F}_{\alpha=C 1 / 12}$, depicted in Fig. 7 and 8, mimic the patterns of the coupled experiments fairly closely. In particular, the spatial distributions of the December to February (DJF) mean $s_{s t}$ values in both experiments $\mathrm{C} 1 / 4$ and $\mathrm{F}_{\alpha=C 1 / 4}$ show large negative values up to -3 in the Gulf Stream and Kuroshio regions as well as in the ACC. A notable deviation concerns the ACC region where the forced experiments tend to underestimate the $s_{s t}$-values obtained in the coupled experiments.

A more quantitative comparison of the different experiments is given in Fig. 9, showing histograms of $s_{s t}$. Both the absolute and relative winds experiments do not compare well with the coupled experiments with global mean values of $s_{s t}=-0.02$ $\left(\mathrm{F}_{\alpha=0}\right)$ and $s_{s t}=-2.30\left(\mathrm{~F}_{\alpha=1}\right)$. Better results are given by the experiments where we estimated the $\alpha$-values from the coupled experiments. While the global mean of $s_{s t}$ in $\mathrm{F}_{\alpha=C 1 / 4}(-1.53)$ are very close to the global mean of $\mathrm{C} 1 / 4(-1.51)$, for $\mathrm{F}_{\alpha=C 1 / 12}$ 


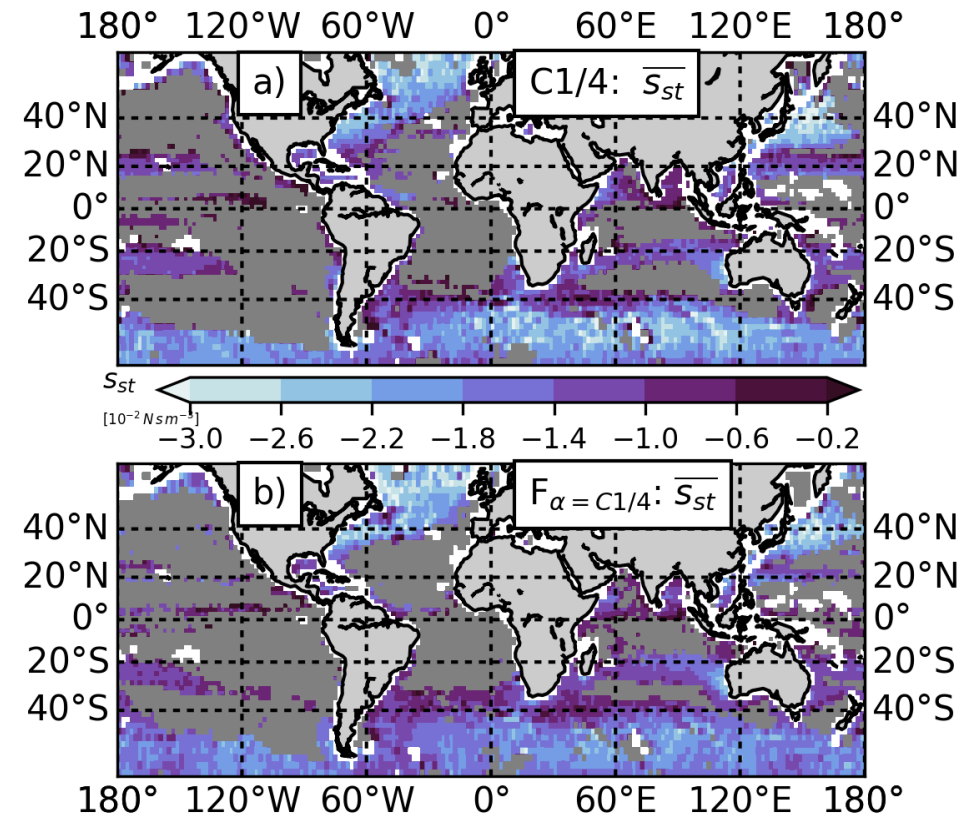

Figure 7. Mean of $s_{s t}$ DJF monthly values for (a) C1/4 and (c) $\mathrm{F}_{\alpha=C 1 / 4}$. Grey areas as in Fig. 2.

$(-1.61)$ there is a slightly larger difference to $\mathrm{C} 1 / 12(-1.51)$. The distributions show small differences: for $s_{s t}$ values between -2.25 and -1.5 the forced experiments have higher PDE when compared to the coupled experiments. It is likely that the differences in background winds are contributing to the differences in the distributions (not shown).

This first assessment of the idea by Renault et al. (2016b) to modify the momentum flux formulation for forced ocean models to account for the re-energisation found in coupled shows that the relationship between the curl of the surface currents and the curl of the surface stress gets closer to the coupled model experiments when using the Renault et al. (2016b) approach. This has implications for the ocean simulation in forced models and in particular for the energetics of the surface ocean. Impacts on the surface EKE are discussed in the following section. 


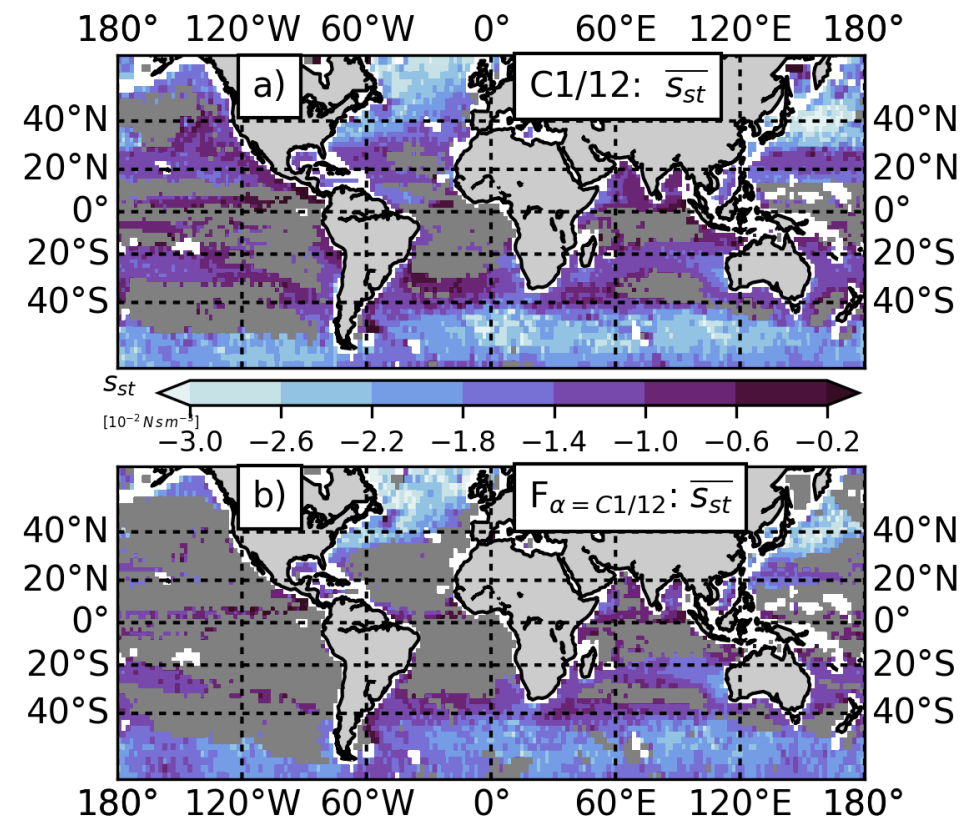

Figure 8. Mean of $s_{s t}$ DJF monthly values for (a) $\mathrm{C} 1 / 12$ and (c) $\mathrm{F}_{\alpha=C 1 / 12}$. Grey areas as in Fig. 2.

\subsection{Assessment of impacts in a forced ocean model}

The strength of the coupling between the curl of the ocean current and the curl of the surface stress (i.e., the choice of $\alpha$ ) has implications for the ocean energetics. The part of the surface stress that is due to ocean surface currents acts as a damping mechanism for surface currents, hence for a larger $\alpha$ we expect to get a stronger damping, i.e., a weaker EKE. This is illustrated

5 in Fig. 10a, by depicting the surface EKE (derived from the velocity deviations from annual mean velocity, based on time series of 5-day mean values) over the Gulf Stream. $\mathrm{F}_{\alpha=1}\left(\mathrm{~F}_{\alpha=0}\right)$ produces the lowest (highest) level of EKE, while $\mathrm{F}_{\alpha=C 1 / 4}$ and $\mathrm{F}_{\alpha=C 1 / 12}$ lie in between, relatively, close to $\mathrm{F}_{\alpha=1}$. A spatial view is given by a meridional section in the Pacific composed of a section through the Kuroshio Extension region at $218^{\circ} \mathrm{W}$ and a section cutting through the equatorial and ACC region at $175^{\circ} \mathrm{W}$ (Fig. 10 b). EKE levels are everywhere largest for $\mathrm{F}_{\alpha=0}$ and smallest for $\mathrm{F}_{\alpha=1}$, while $\mathrm{F}_{\alpha=C 1 / 4}$ and $\mathrm{F}_{\alpha=C 1 / 12}$ values lie in between. More specifically, regional averages in EKE and mean kinetic energy (MKE) for $\mathrm{F}_{\alpha=C 1 / 4}\left(\mathrm{~F}_{\alpha=C 1 / 12}\right)$ show increases by $6 \%(6 \%)$ and $1 \%(1 \%)$ in the $\mathrm{ACC}, 12 \%(9 \%)$ and $2 \%(5 \%)$ in the Kuroshio, $15 \%(16 \%)$ and $-1 \%(-1 \%)$ in the Gulf Stream, and $14 \%(12 \%)$ and $9 \%(8 \%)$ in the equatorial region $\left( \pm 5^{\circ}\right.$ off the equator). A switch from relative to absolute winds shows even stronger changes in EKE and MKE. Direct comparison of EKE to the coupled simulations is not meaningful 
Ocean Sci. Discuss., doi:10.5194/os-2017-24, 2017

Manuscript under review for journal Ocean Sci.

Discussion started: 12 April 2017

(C) Author(s) 2017. CC-BY 3.0 License.

Discussions

(c) (i)

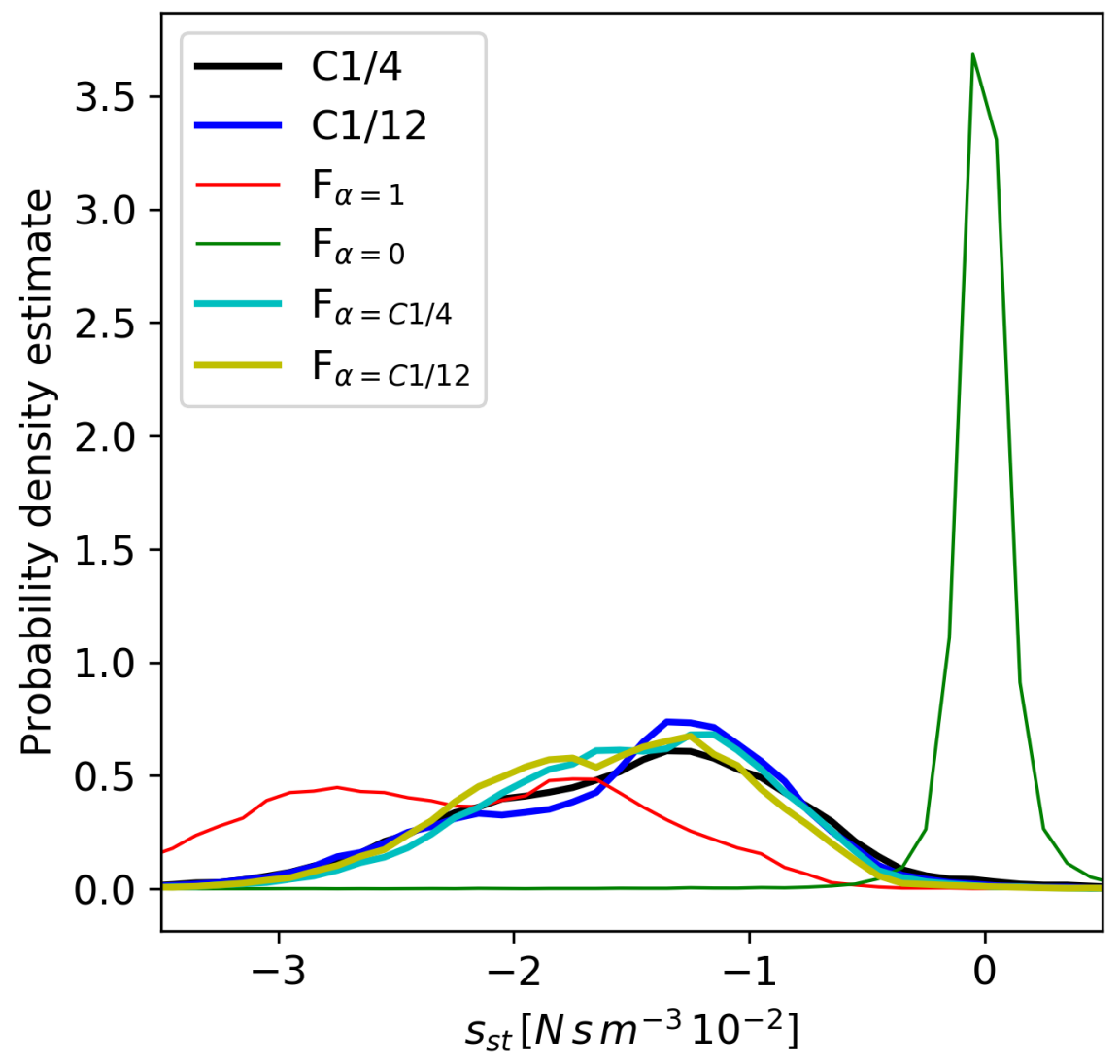

Figure 9. Normalized histogram (or probability density estimate) of ocean-surface current and surface stress coupling coefficient $s_{s t}$ for $2^{\circ} \times 2^{\circ}$ boxes from $60^{\circ} \mathrm{S}$ to $60^{\circ} \mathrm{N}$ (to exclude sea-ice regions; grey areas in Fig. 2 are excluded).

here because differences in resolution and frequency of wind forcing (Hughes and Wilson, 2008; Zhai et al., 2012) and details of the ocean configurations account for larger differences in EKE than the choice of $\alpha$.

\section{Discussion}

In two coupled high resolution ocean models, we find a linkage between ocean surface currents and surface winds with pro-

5 nounced spatio-temporal variability. The strength of the coupling coefficient $s_{w}$ appears strongly affected by the atmospheric stability. The present results extend the findings of the regional model study of Renault et al. (2016b) to the global oceanatmosphere system. By including this feedback in the bulk formulation of the momentum flux (1), with $\alpha=1-s_{w}$, using the spatially and temporally varying coefficient $s_{w}$ estimated from the coupled models, the forced models appeared to capture 

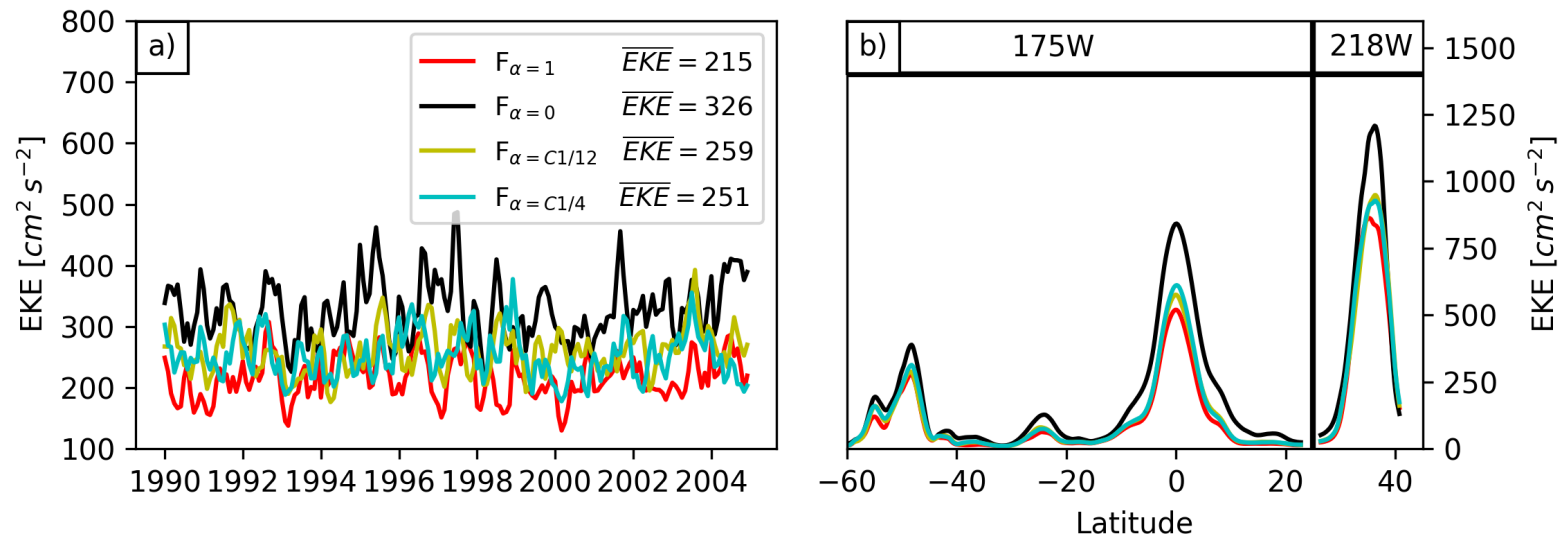

Figure 10. Surface eddy kinetic energy (EKE) for (a) the Gulf Stream $\left(35-45^{\circ} \mathrm{N}, 37-75^{\circ} \mathrm{W}\right)$ and at (b) a meridional section through the Kuroshio region $\left(218^{\circ} \mathrm{W}\right)$ and through the equatorial and ACC region $\left(175^{\circ} \mathrm{W}\right)\left(1990-2004\right.$ mean). Experiments shown are $\mathrm{F}_{\alpha=0}(\mathrm{black})$, $\mathrm{F}_{\alpha=1}(\mathrm{red}), \mathrm{F}_{\alpha=C 1 / 4}$ (green) and $\mathrm{F}_{\alpha=C 1 / 12}$ (yellow).

the principal features of the coupling $s_{s t}$ for energetic oceanic regions. A first consequence of the 're-energisation tweak' is a slight, $\mathrm{O}(10 \%)$ increase in EKE and MKE for the energetic current regions compared to the 'relative wind' formulation used in current ocean modelling practice.

We note several limitations of the method applied here: (1) For small curls of the ocean currents, the coupling coefficients appear to be biased, and cannot be robustly estimated (cf. Fig. A2). (2) The temporal and spatial scales of the atmosphere and ocean are not entirely separated. Therefore the results slightly vary with the cut-off length of the filter. (3) The results may depend on the parameterization of the vertical momentum flux in the atmospheric model. Further research should examine turbulence resolving atmospheric models, perhaps in conjunction with prescribed ocean currents, to understand how the state of the atmosphere modifies the response of near-surface winds in the presence of ocean currents.

5 The simulations presented here clearly show an imprint of the ocean surface currents on the surface stress and the near-surface winds. Estimates of surface stress (e.g., from scatterometer measurements) or the winds simulated in coupled simulations should thus be regarded as containing an imprint of the surface ocean state. Using either of these to drive an ocean-only model may have undesirable effects because it provides a spurious source of energy to the ocean model (Xu and Scott, 2008). On the other hand, in data sets produced for the forcing of ocean models (e.g. Large and Yeager, 2004; Brodeau et al., 2010) winds are corrected by scatterometer derived winds only on larger scales for which the feedback from ocean surface currents should be small.

The present results support the proposition of Renault et al. (2016b) that the surface boundary condition for momentum in ocean-only simulations should include the surface current feedback to the wind. In contrast to a recent recommendation

5 (WCRP, 2015) to use 'absolute winds' to avoid imprints of ocean currents in the wind/wind-stress, our results suggest a revi- 
Ocean Sci. Discuss., doi:10.5194/os-2017-24, 2017

Manuscript under review for journal Ocean Sci.

Discussion started: 12 April 2017

(c) Author(s) 2017. CC-BY 3.0 License.

(c) $($ P)

sion of the 'relative winds'-formulation in the form of (1) with $\alpha=1-s_{w}$, using a variable coefficient $s_{w}$ in conjunction with winds from reanalysis products (where the atmosphere is forced only by SST) to force global ocean-sea ice models. The possibility of developing a parameterization for $s_{w}$ based on atmospheric state parameters needs to be explored in further studies.

\section{Code availability}

The plotting routines are available from https://github.com/RafaelAbel/current_feedback_on_winds

\section{Data availability}

The time and space variable $\alpha$ datasets are available from https://data.geomar.de/thredds/catalog/open_access/abel_et_al_ 2017_os/catalog.html

\section{Appendix A: Energy spectra}

An inspection of high-resolution coupled model output (Fig. A1) suggests an upper bound of about 200km for the transition between wavelengths where the atmosphere is more energetic and wavelengths where the ocean is more energetic. We find that this scale separation is sometimes more pronounced and in some regions not even valid and show this exemplarily for three locations: in a large box in the South Pacific, the atmospheric velocity spectral density dominates at all scales; in a rather small box in the North Pacific, we find a transition from atmospheric domination to oceanic domination at wavelengths of about $200 \mathrm{~km}$; in the Gulf Stream Extension, below wavelengths of $150 \mathrm{~km}$, atmospheric and oceanic velocity spectral densities are at the same level. As we are attempting to find a signal that is imprinted by the ocean on the atmosphere we need to consider energetic regions of the ocean. With conditions such as in the South Pacific, we will not be able to detect the oceanic imprint (discussed in Appendix B).

\section{Appendix B: Biased scatter plots}

As seen in Fig. 1 the relationship between curl(u) and curl(wind) does not follow exactly the suggested linear fit. This becomes particularly problematic if curl(u), i.e. the spread along the x-axis, is relatively small. With small curl(u) the estimation of the slope of the linear regression tends to be biased towards large values. This can be seen when mapping the maximum difference between curl(u) values to the estimated $s_{w}$ (Fig. A2). There we see that $s_{w}$ and $\sigma\left(s_{w}\right)$ get large if $|\operatorname{curl}(u)|<1$. We choose to ignore these values and mark them as grey areas in the figures with global maps. 
Ocean Sci. Discuss., doi:10.5194/os-2017-24, 2017

Manuscript under review for journal Ocean Sci.

Discussion started: 12 April 2017

(c) Author(s) 2017. CC-BY 3.0 License.
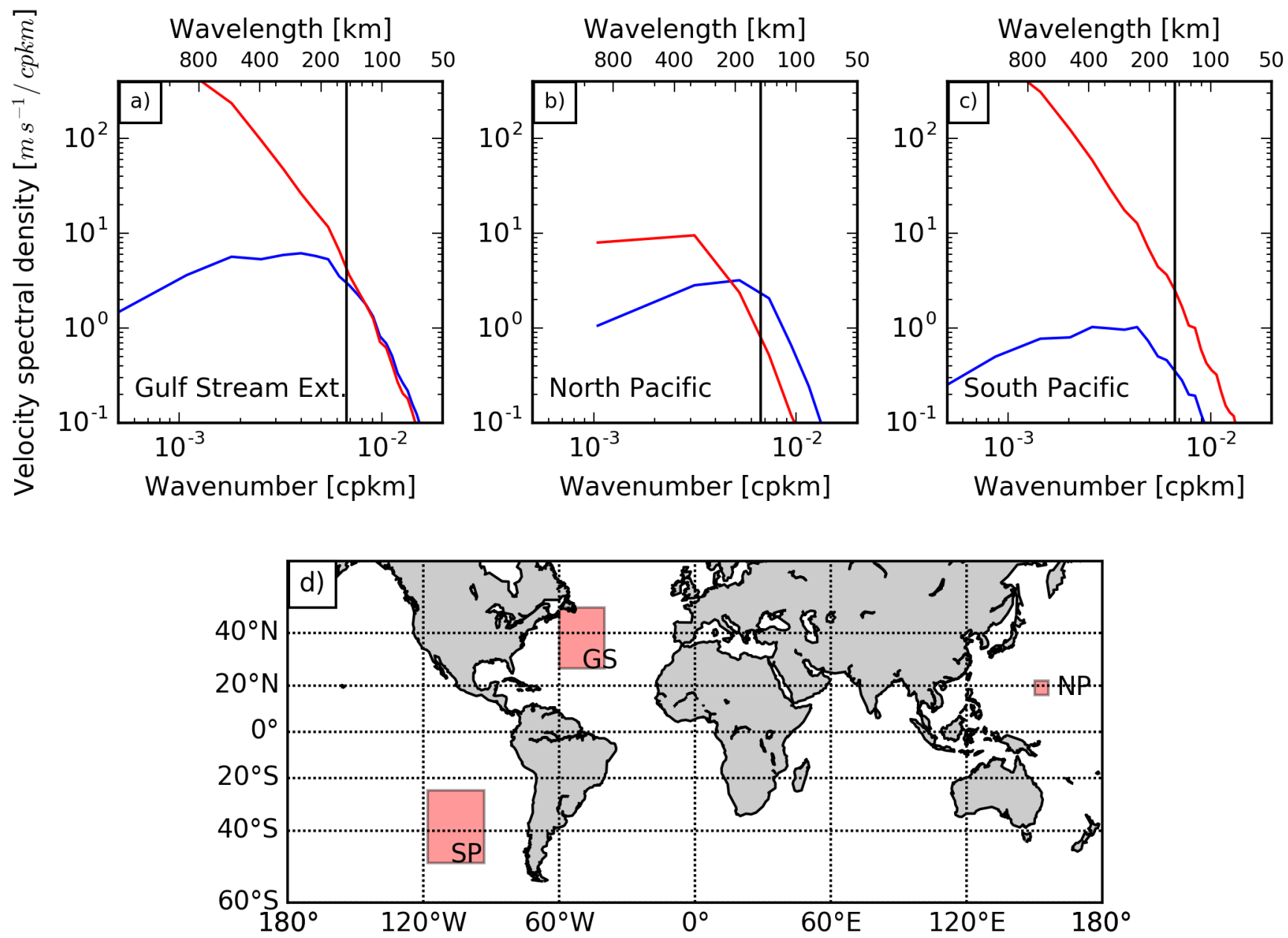

Figure A1. Isotropic wavenumber spectra of ocean velocity (blue) and wind speed (red) for (a) South Pacific, (b) North Pacific and (c) Gulf Stream Extension in C1/4 monthly output. In d) you find the exact positions of the boxes. Vertical black lines represent the $150 \mathrm{~km}$ wavelength to illustrate the cutoff length of the high-pass filter used for this study. The idea of using a high-pass filter is to exclude wavelengths where atmospheric variability is larger than oceanic. We see in the north Pacific (b) that at higher wavenumbers oceanic spectral density is larger that atmospheric and in the Gulf Stream Extension (c) they have the same order of magnitude. The 150km high-pass filter seems to be a good choice for the North Pacific box and for the Gulf Stream Extension box. In the South Pacific atmospheric variability dominates at all wavenumbers. This is also a region where we were not able to estimate coupling coefficients (see Fig 2). 
Ocean Sci. Discuss., doi:10.5194/os-2017-24, 2017

Manuscript under review for journal Ocean Sci.

Discussion started: 12 April 2017

(C) Author(s) 2017. CC-BY 3.0 License.
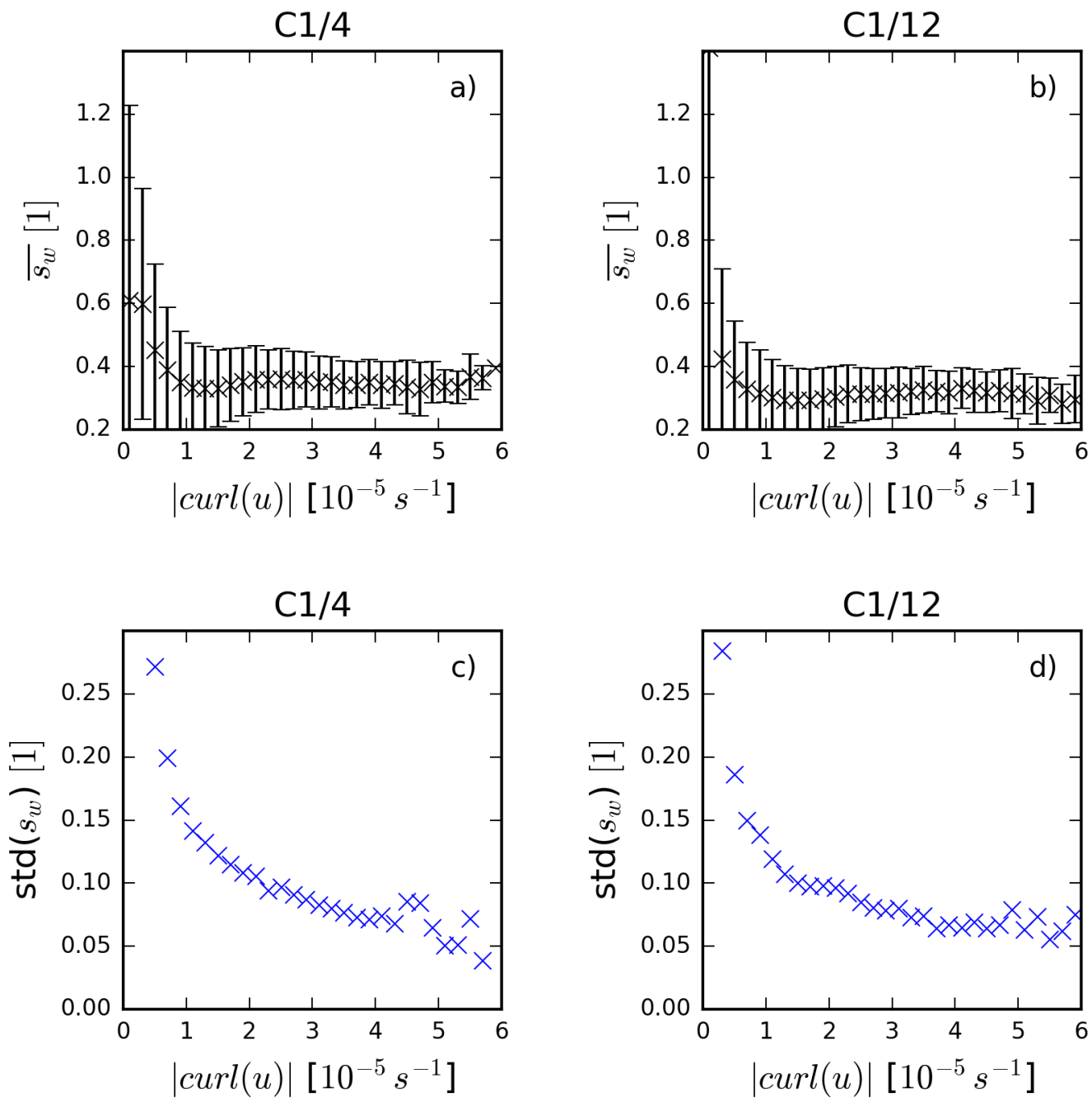

Figure A2. Coupling coefficient $s_{w}$ as a function of absolute value of curl(u) for (a) C1/4, (b) C1/12 and standard deviation of $s_{w}$ for (c) $\mathrm{C} 1 / 4$, (d) $\mathrm{C} 1 / 12$. For small $|\operatorname{curl}(u)| s_{w}$ and $\sigma\left(s_{w}\right)$ get larger. We see this as a problem of the method and therefore neglect values where range $|\operatorname{curl}(u)|<1$. Similar behaviour is seen for $s_{s t}$ and neglected as well. This results in the grey areas in Fig. 2,5 and 6. 
Ocean Sci. Discuss., doi:10.5194/os-2017-24, 2017

Manuscript under review for journal Ocean Sci.

Discussion started: 12 April 2017

(c) Author(s) 2017. CC-BY 3.0 License.

\section{Appendix C: Degrees of Freedom estimation}

The standard error of the slope of the linear regression is estimated by:

$S E=\sqrt{\frac{S S_{y} / S S_{x}-b^{2}}{D O F}}$,

where $S S_{y}=\sum\left(y_{i}-\bar{y}_{i}\right)^{2}, S S_{y}=\sum\left(x_{i}-\bar{x}_{i}\right)^{2},{ }^{-}$denotes mean, $\mathrm{b}$ is slope of linear regression and DOF are the degrees of freedom (DOF).

Given any three dimensional data set (two space and one time dimension) there will be coherence, meaning that time and space points can be dependent on each other. Therefore the DOF estimation needs to consider both temporal and spatial DOF. For the temporal DOF of freedom we follow Bretherton et al. (1999), estimating the ratio of effective sample size (ESS, $N^{*}$ ) to sample size $\mathrm{N}$

$N^{*} / N=\frac{1-r_{1} r_{2}}{1+r_{1} r_{2}}$

while $r_{1,2}$ is the lag-one autocorrelation for dataset 1,2 . If only one dataset is used $r_{1}=r_{2}$. For the spatial DOF estimation we use an adapted binomial method (B-method) of Livezey and Chen (1983) and Wang and Shen (1999), where a random time series is correlated with every spatial point since by chance some points will give a significant correlation with that random time series, the points with significant correlation share coherence, which is exploited to estimate the coherence of the field. To estimate the total DOF of the given three-dimensional (with two spatial and one temporal dimension $t$ ) climate data set we combine the spatial $\left(D O F_{S}\right)$ and temporal DOF estimation

$5 \quad D O F_{\text {total }}=D O F_{S} \cdot t \cdot N^{*} / N$

Details of the estimation and a python-based program can be found at https://github.com/RafaelAbel/DOF_estimation.

Author contributions. R.A. conceived the project, run the ocean-only experiments, carried out the analysis and wrote the initial draft. C.W.B. and R.J.G. contributed to refining the ideas and shape the manuscript. H.T.H. and M.J.R. designed and run the coupled experiments. All authors contributed to writing this paper.

Acknowledgements. This study is a contribution to the cooperative project RACE II (Regional Atlantic Circulation and Global Change, grant 03F0729C). This study has also been supported by the German Ministry for Education and Research (BMBF) through MiKlip2, subproject 01LP1517D (ATMOSMODINI), and SACUS (03G0837A), and by the European Union 7th Framework Programme (FP7 2007-2013) under grant agreement 603521 PREFACE project. Met Office authors were supported by the Joint DECC/Defra Met Office Hadley Centre Climate Programme (GA01101), and M.J.R. was also part funded through the PRIMAVERA project under Grant Agreement 641727 in the European 
Ocean Sci. Discuss., doi:10.5194/os-2017-24, 2017

Manuscript under review for journal Ocean Sci.

Discussion started: 12 April 2017

(c) Author(s) 2017. CC-BY 3.0 License.

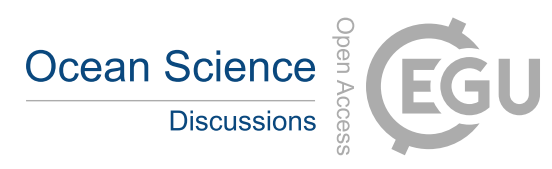

(c) (i)

along with the corresponding support teams. The forced model system has been developed by the ocean modeling group at GEOMAR in the framework of the DRAKKAR collaboration. The forced simulations were performed at the Christian-Albrechts-Universität zu Kiel. R.A. thanks Willi Rath, John Edwards, Bernard Barnier, Julien Le Sommer, Florian Lemarié and Lionel Renault for helpful discussions. 
Ocean Sci. Discuss., doi:10.5194/os-2017-24, 2017

Manuscript under review for journal Ocean Sci.

Discussion started: 12 April 2017

(c) Author(s) 2017. CC-BY 3.0 License.

\section{References}

Bretherton, C. S., M. Widmann, V. P. Dymnikov, J. M. Wallace, and I. Bladé (1999), The effective number of spatial degrees of freedom of a time-varying field, J. Clim., 12(7), 1990-2009, doi:10.1175/1520-0442(1999)012<1990:TENOSD>2.0.CO;2.

Brodeau, L., B. Barnier, A.-M. Treguier, T. Penduff, and S. Gulev (2010), An ERA40-based atmospheric forcing for global ocean circulation models, Ocean Model., 31(3-4), 88-104, doi:10.1016/j.ocemod.2009.10.005.

Bryan, F. O., R. Tomas, J. M. Dennis, D. B. Chelton, N. G. Loeb, and J. L. Mcclean (2010), Frontal scale air-sea interaction in high-resolution coupled climate models, J. Clim., 23(23), 6277-6291, doi:10.1175/2010JCLI3665.1.

Byrne, D., M. Munnich, I. Frenger, and N. Gruber (2016), Mesoscale atmosphere ocean coupling enhances the transfer of wind energy into the ocean, Nat. Commun., (May), 1-8, doi:10.1038/ncomms11867.

Chelton, D. B., M. G. Schlax, M. H. Freilich, and R. F. Milliff (2004), Satellite measurements reveal persistent small-scale features in ocean winds., Science, 303(5660), 978-83, doi:10.1126/science.1091901.

Chelton, D. B., M. G. Schlax, and R. M. Samelson (2007), Summertime Coupling between Sea Surface Temperature and Wind Stress in the California Current System, J. Phys. Oceanogr., 37(3), 495-517, doi:10.1175/JPO3025.1.

Dewar, W. K., and G. R. Flierl (1987), Some Effects of the Wind on Rings, J.Phys. Oceanogr., 17, 1653-67, doi:10.1175/1520-0485(1987) 017.

Duhaut, T., and D. Straub (2006), Wind Stress Dependence on Ocean Surface Velocity: Implications for Mechanical Energy Input to Ocean Circulation, J. Phys. Oceanogr., 36, 202-211, doi:10.1175/JPO2842.1.

Eden, C., and H. Dietze (2009), Effects of mesoscale eddy/wind interactions on biological new production and eddy kinetic energy, J. Geophys. Res., 114(C5), C05,023, doi:10.1029/2008JC005129.

20 Frenger, I., N. Gruber, R. Knutti, and M. Münnich (2013), Imprint of Southern Ocean eddies on winds, clouds and rainfall, Nat. Geosci., 6(8), 608-612, doi:10.1038/ngeo1863.

Griffies, S. M., A. Biastoch, C. Böning, F. Bryan, G. Danabasoglu, E. P. Chassignet, M. H. England, R. Gerdes, H. Haak, R. W. Hallberg, W. Hazeleger, J. Jungclaus, W. G. Large, G. Madec, A. Pirani, B. L. Samuels, M. Scheinert, A. S. Gupta, C. a. Severijns, H. L. Simmons, A. M. Treguier, M. Winton, S. Yeager, and J. Yin (2009), Coordinated Ocean-ice Reference Experiments (COREs), Ocean Model., 26(1-2), 1-46, doi:10.1016/j.ocemod.2008.08.007.

Hewitt, H. T., M. J. Roberts, P. Hyder, T. Graham, J. Rae, S. E. Belcher, R. Bourdalle-Badie, D. Copsey, A. Coward, C. Guiavarch, C. Harris, R. Hill, J. J.-M. Hirschi, G. Madec, M. S. Mizielinski, E. Neininger, A. L. New, J.-C. Rioual, B. Sinha, D. Storkey, A. Shelly, L. Thorpe, and R. A. Wood (2016), The impact of resolving the Rossby radius at mid-latitudes in the ocean: results from a high-resolution version of the Met Office GC2 coupled model, Geosci. Model Dev. Discuss., (April), 1-35, doi:10.5194/gmd-2016-87.

Hughes, C. W., and C. Wilson (2008), Wind work on the geostrophic ocean circulation: An observational study of the effect of small scales in the wind stress, J. Geophys. Res., 113(C2), 1-10, doi:10.1029/2007JC004371.

Hutchinson, D. K., A. M. C. Hogg, and J. R. Blundell (2010), Southern Ocean Response to Relative Velocity Wind Stress Forcing, J. Phys. Oceanogr., 40(2), 326-339, doi:10.1175/2009JPO4240.1.

Large, W., and S. Yeager (2004), Diurnal to Decadal Global Forcing For Ocean and Sea-Ice Models : The Data Sets and Flux Climatologies, NCAR Technical Note NCAR/TN-460+STR, doi:10.5065/D6KK98Q6

Large, W. G., and S. G. Yeager (2009), The global climatology of an interannually varying air-sea flux data set, Clim. Dyn., 33(2-3), 341-364, doi:10.1007/s00382-008-0441-3. 
Ocean Sci. Discuss., doi:10.5194/os-2017-24, 2017

Manuscript under review for journal Ocean Sci.

Discussion started: 12 April 2017

(c) Author(s) 2017. CC-BY 3.0 License.

Livezey, R. E., and W. Y. Chen (1983), Statistical Field Significance and its Determination by Monte Carlo Techniques, Mon. Weather Rev., 111(1), 46-59, doi:10.1175/1520-0493(1983)111<0046:SFSAID>2.0.CO;2.

Luo, J.-J., S. Masson, E. Roeckner, G. Madec, T. Yamagata, and P. Science (2004), Reducing Climatology Bias in an Ocean - Atmosphere CGCM with Improved, J. Clim., 18, 2344-2360, doi:10.1175/JCLI3404.1.

5 Ma, X., Z. Jing, P. Chang, X. Liu, R. Montuoro, R. J. Small, F. O. Bryan, R. J. Greatbatch, P. Brandt, D. Wu, X. Lin, and L. Wu (2016), Western boundary currents regulated by interaction between ocean eddies and the atmosphere, Nature, 535(7613), 533-537, doi:10.1038/nature18640.

Madec, G. (2011), NEMO ocean engine, 27, tech. rep. ed., Inst. Pierre-Simon Laplace (IPSL), France.

Minobe, S., A. Kuwano-Yoshida, N. Komori, S.-P. Xie, and R. J. Small (2008), Influence of the Gulf Stream on the troposphere., Nature, 452(7184), 206-9, doi:10.1038/nature06690.

Moulin, A., and A. Wirth (2016), Momentum Transfer Between an Atmospheric and an Oceanic Layer at the Synoptic and the Mesoscale: An Idealized Numerical Study, Boundary-Layer Meteorol., pp. 1-18, doi:10.1007/s10546-016-0153-x.

Pacanowski, R. C. (1987), Effect of Equatorial Currents on Surface Stress, J. Phys. Oceanogr., 17, 833-838, doi:10.1175/15200485(1987)017.

15 Perlin, N., E. D. Skyllingstad, R. M. Samelson, and P. L. Barbour (2007), Numerical Simulation of Air-Sea Coupling during Coastal Upwelling, J. Phys. Oceanogr., 37(8), 2081-2093, doi:10.1175/JPO3104.1.

Rath, W., R. J. Greatbatch, and X. Zhai (2013), Reduction of near-inertial energy through the dependence of wind stress on the ocean-surface velocity, J. Phys. Ocean., 118(6), 2761-2773, doi:10.1002/jgrc.20198.

Renault, L., A. Hall, and J. C. McWilliams (2016a), Orographic shaping of US West Coast wind profiles during the upwelling season, Clim. Dyn., pp. 1-17, doi:10.1007/s00382-015-2583-4.

Renault, L., M. J. Molemaker, J. C. McWilliams, A. F. Shchepetkin, F. Lemarié, D. Chelton, S. Illig, and A. Hall (2016b), Modulation of Wind-Work by Oceanic Current Interaction with the Atmosphere, J. Clim., pp. 0-52, doi:10.1175/JPO-D-15-0232.1.

Roberts, M. J., H. T. Hewitt, P. Hyder, D. Ferreira, S. A. Josey, M. Mizielinski, and A. Shelly (2016), Impact of ocean resolution on coupled air-sea fluxes and large-scale climate, Geophys. Res. Lett., doi:10.1002/2016GL070559.

25 Samelson, R. M., E. D. Skyllingstad, D. B. Chelton, S. K. Esbensen, L. W. O’Neill, and N. Thum (2006), On the coupling of wind stress and sea surface temperature, J. Clim., 19(8), 1557-1566, doi:10.1175/JCLI3682.1.

Scott, R. B., and Y. Xu (2009), An update on the wind power input to the surface geostrophic flow of the World Ocean, Deep. Res. Part I Oceanogr. Res. Pap., 56(3), 295-304, doi:10.1016/j.dsr.2008.09.010.

Seo, H., A. J. Miller, and J. R. Norris (2016), Eddy-wind interaction in the California Current System: dynamics and impacts, J. Phys. Oceanogr., (1989), 151130150615,002, doi:10.1175/JPO-D-15-0086.1.

Shuckburgh, E., G. Maze, D. Ferreira, J. Marshall, H. Jones, and C. Hill (2011), Mixed Layer Lateral Eddy Fluxes Mediated by Air-Sea Interaction, J. Phys. Oceanogr., 41(1), 130-144, doi:10.1175/2010JPO4429.1.

Small, R., S. DeSzoeke, S. Xie, L. O’Neill, H. Seo, Q. Song, P. Cornillon, M. Spall, and S. Minobe (2008), Air-sea interaction over ocean fronts and eddies, Dyn. Atmos. Ocean., 45(3-4), 274-319, doi:10.1016/j.dynatmoce.2008.01.001.

35 Smith, S. D. (1988), Coefficients for sea surface wind stress, heat flux, and wind profiles as a function of wind speed and temperature, J. Geophys. Res. Ocean., 93(C12), 15,467-15,472, doi:10.1029/JC093iC12p15467.

Spall, M. a. (2007), Midlatitude Wind Stress-Sea Surface Temperature Coupling in the Vicinity of Oceanic Fronts, J. Clim., 20(15), 37853801, doi:10.1175/JCLI4234.1. 
Ocean Sci. Discuss., doi:10.5194/os-2017-24, 2017

Manuscript under review for journal Ocean Sci.

Discussion started: 12 April 2017

(c) Author(s) 2017. CC-BY 3.0 License.

(c) (i)

Wallace, J. M., T. P. Mitchell, and C. Deser (1989), The Influence of Sea-Surface Temperature on Surface Wind in the Eastern Equatorial Pacific: Seasonal and Interannual Variability, doi:10.1175/1520-0442(1989)002<1492:TIOSST>2.0.CO;2.

Wang, X., and S. S. Shen (1999), Estimation of spatial degrees of freedom of a climate field, J. Clim., 12(5 I), 1280-1291, doi:10.1175/15200442(1999)012<1280:EOSDOF>2.0.CO;2.

5 WCRP (2015), CLIVAR Ocean Model Development Panel (OMDP) mini workshop on forcing ocean and sea-ice models, WCRP Rep. 9, CLIVAR Rep. 202, 22pp. [Available online at http://www.clivar.org/sites/default/files/documents/OMDP_Grenoble_report.pdf]

Xie, S. P. (2004), Satellite observations of cool ocean-atmosphere interaction, Bull. Am. Meteorol. Soc., 85(2), 195-208, doi:10.1175/BAMS85-2-195.

Xu, Y., and R. B. Scott (2008), Subtleties in forcing eddy resolving ocean models with satellite wind data, Ocean Model., 20(3), 240-251, doi:10.1016/j.ocemod.2007.09.003.

Zhai, X., and R. J. Greatbatch (2007), Wind work in a model of the northwest Atlantic Ocean, Geophys. Res. Lett., 34(4), 1-4, doi:10.1029/2006GL028907.

Zhai, X., H. L. Johnson, D. P. Marshall, and C. Wunsch (2012), On the Wind Power Input to the Ocean General Circulation, J. Phys. Oceanogr., 42(8), 1357-1365, doi:10.1175/JPO-D-12-09.1. 